Relations industrielles

Industrial Relations

\title{
Gestion Economique des Stocks, A. Rambaux, Deuxième édition, Dunod Paris, 1963, 153 pages.
}

\section{Bertrand Belzile}

Volume 21, numéro 1, 1966

URI : https://id.erudit.org/iderudit/027652ar

DOI : https://doi.org/10.7202/027652ar

Aller au sommaire du numéro

Éditeur(s)

Département des relations industrielles de l'Université Laval

ISSN

0034-379X (imprimé)

1703-8138 (numérique)

Découvrir la revue

Citer ce compte rendu

Belzile, B. (1966). Compte rendu de [Gestion Economique des Stocks, A. Rambaux, Deuxième édition, Dunod Paris, 1963, 153 pages.] Relations industrielles / Industrial Relations, 21(1), 104-104.

https://doi.org/10.7202/027652ar

Tous droits réservés (C) Département des relations industrielles de l'Université Laval, 1966
Ce document est protégé par la loi sur le droit d'auteur. L’utilisation des services d'Érudit (y compris la reproduction) est assujettie à sa politique d'utilisation que vous pouvez consulter en ligne.

https://apropos.erudit.org/fr/usagers/politique-dutilisation/ 
RELATIONS INDUSTRIELLES, vol. 21, No 1

\section{RECENSIONS BOOKS REVIEW}

Gestion Economique des Stocks, A. Rambaux, Deuxième Edition, Dunod Paris, 1963. 153 pages.

Ce petit volume nous apporait accessible à tout lecteur cultivé, comme on peut le lire d'ailleurs dans l'excellente préface de M. Paul Gros, président de la Fédération européenne de l'Approvisionnement. De plus on y trouve un exposé à la fois compréhensif et simple des connaissances fondamentales dans l'important domaine de la gestion des stocks. En effet, il n'y a pas si longtemps déjà, cette fonction se limitait principolement à la comptabilisation des stocks et à leur magasinage. Or, cette gestion « a pour objet précis le maintien du volume des stocks au plus bas niveau, compatible avec, d'une part, l'alimentation régulière de l'Entreprise et, d'autre part, la meilleure exécution des autres sous-fonctions de l'approvisionnement: Achat, Magasinage, etc. 》

Dans une première partie, l'auteur énonce les problèmes posés par la gestion des stocks, entre autres les deux principaux, à sovoir le volume des stocks et leur renouvellement. Dans son introduction, M. Rambaux écrit que "dans leur ensemble, les diverses solutions admises peuvent être classées, très schématiquement, en deux grandes catégories: 1) solutions qui consistent à passer à des dates variables, des commandes d'une quantité fixe donnée arbitrairement ou pouvant résulter d'un calcul; 2) solutions qui consistent à passer à des dates fixes, arbitraires ou non, des commandes de quantités variobles ».

Mais c'est sans aucun doute la deuxième portie intitulée Analyse économique des prob!èmes de gestion de stocks, qui présente le plus d'intérêt et qui occupe d'ailleurs le plus grand espace dans le volume. Un chapitre présente la méthode du calcul des quantités économiques à commander et un autre celle du calcul de la périodicité économique des commandes. Dans l'un et l'autre cas, il fout tenir compte de tous les éléments du coût de possession d'un stock et du coût de passation des commandes de renouvellement. Ces deux méthodes de calcul constituent l'essentiel de la deuxième partie, sans négliger toutefois les autres chapitres qui s'y trouvent.

Enfin, la troisième partie traite de la mise en place pratique d'un plan d'approvisionnement.

Répétons que ce petit volume, fort bien fait d'ailleurs et facilement accessible à tout lecteur cultivé, ne comprend quond même que les connaissances fondamentales dans la gestion des stocks. Plusieurs nouveaux modèles plus ou moins élaborés apparaissent qui tiennent compte davantage, pour la plupart, du caractère aléatoire de l'écoulement des stocks et des délais de renouvellement.

\section{Bertrand Belzile}

\section{Choisissez votre carrière pour diplômés uni-} versitaires 1966. Cornmarket Press (Canada) Limited, 820 Place Ville Marie, Montréal 2, Qué. 1965. 230 poges.

Rares sont les diplômés d'université des récentes années qui $n^{\prime}$ ont pas eu quelques occasions de connaitre le genre de littérature que nous présente a choisissez votre carrière ». Mais pour ceux qui n'ont pas eu l'occosion de connaître cet excellent ouvrage de référence, mentionnons-en quelques avantages.

En plus de présenter à ces diplômés une liste des plus complètes concernont les offres d'emploi relatives à toutes les carrières possibles, cette publication fournit une occasion aux employeurs de se mieux faire connaitre. Ils peuvent ainsi copter une des meilleures opportunités de recruter les gens de compétence dont ils ont un besoin pressant et constant.

Publié annuellement par une agence canadienne "choisissez votre carrière » contient également d'excellents textes composés par des personnes éminentes dans le domaine du placement des travailleurs et de l'enseignement universitaire. Nous trouvons dans une première section, d'intéressants conseils sur le choix d'un emploi. $C^{\prime}$ est oussi ò travers ces textes que nous aurons une meilleure vision des grands domaines d'activités des diplômés d'université, 